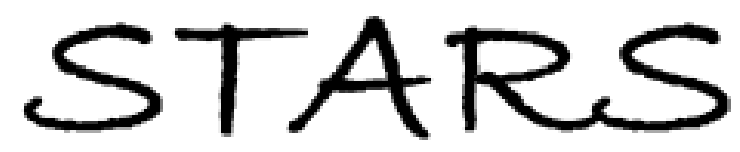

University of Central Florida

STARS

$1-1-2010$

\title{
B diffusion in implanted Ni2Si and NiSi layers
}

I. Blum

\author{
A. Portavoce \\ L. Chow \\ University of Central Florida \\ D. Mangelinck \\ K. Hoummada
}

See next page for additional authors

Find similar works at: https://stars.library.ucf.edu/facultybib2010 University of Central Florida Libraries http://library.ucf.edu

This Article is brought to you for free and open access by the Faculty Bibliography at STARS. It has been accepted for inclusion in Faculty Bibliography 2010 s by an authorized administrator of STARS. For more information, please contact STARS@ucf.edu.

\section{Recommended Citation}

Blum, I.; Portavoce, A.; Chow, L.; Mangelinck, D.; Hoummada, K.; Tellouche, G.; and Carron, V., "B diffusion in implanted Ni2Si and NiSi layers" (2010). Faculty Bibliography 2010s. 7005.

https://stars.library.ucf.edu/facultybib2010/7005

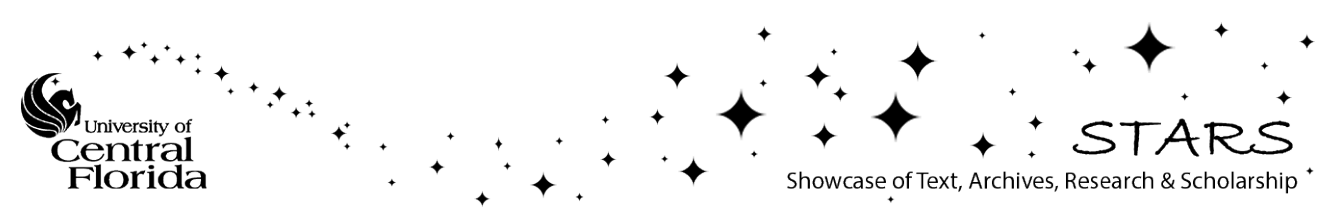


Authors

I. Blum, A. Portavoce, L. Chow, D. Mangelinck, K. Hoummada, G. Tellouche, and V. Carron 


\section{B diffusion in implanted $\mathrm{Ni}_{2} \mathrm{Si}$ and $\mathrm{NiSi}$ layers}

Cite as: Appl. Phys. Lett. 96, 054102 (2010); https://doi.org/10.1063/1.3303988

Submitted: 09 November 2009 . Accepted: 11 January 2010 . Published Online: 04 February 2010

I. Blum, A. Portavoce, L. Chow, D. Mangelinck, K. Hoummada, G. Tellouche, and V. Carron

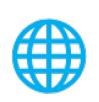

View Online

\section{ARTICLES YOU MAY BE INTERESTED IN}

Effect of Pt addition on Ni silicide formation at low temperature: Growth, redistribution, and solubility

Journal of Applied Physics 106, 063511 (2009); https://doi.org/10.1063/1.3204948

Kinetics of a transient silicide during the reaction of Ni thin film with (100)Si

Applied Physics Letters 95, 181902 (2009); https://doi.org/10.1063/1.3257732

Thin film reaction of transition metals with germanium

Journal of Vacuum Science \& Technology A 24, 474 (2006); https://doi.org/10.1116/1.2191861

\section{Applied Physics Reviews} Now accepting original research 


\title{
B diffusion in implanted $\mathrm{Ni}_{2} \mathrm{Si}$ and $\mathrm{NiSi}$ layers
}

\author{
I. Blum, ${ }^{1}$ A. Portavoce, ${ }^{2, a)}$ L. Chow ${ }^{3}$ D. Mangelinck, ${ }^{2}$ K. Hoummada, ${ }^{1}$ G. Tellouche, ${ }^{1}$ and \\ V. Carron ${ }^{4}$ \\ ${ }^{1}$ IM2NP, Faculté des Sciences de Saint-Jérôme, Aix-Marseille Université, Case 142, \\ 13397 Marseille, France \\ ${ }^{2}$ IM2NP, Faculté des Sciences de Saint-Jérôme, CNRS, Case 142, 13397 Marseille, France \\ ${ }^{3}$ Department of Physics, University of Central Florida, Orlando, Florida 32816, USA \\ ${ }^{4}$ CEA-LETI, MINATEC, 17 rue des Martyrs, 38054 Grenoble Cedex 9, France
}

(Received 9 November 2009; accepted 11 January 2010; published online 4 February 2010)

\begin{abstract}
B diffusion in implanted $\mathrm{Ni}_{2} \mathrm{Si}$ and $\mathrm{NiSi}$ layers has been studied using secondary ion mass spectrometry, and compared to $\mathrm{B}$ redistribution profiles obtained after the reaction of a $\mathrm{Ni}$ layer on a B-implanted $\mathrm{Si}(001)$ substrate, in same annealing conditions $\left(400-550{ }^{\circ} \mathrm{C}\right)$. B diffusion appears faster in $\mathrm{Ni}_{2} \mathrm{Si}$ than in NiSi. The B solubility limit is larger than $10^{21}$ atom $\mathrm{cm}^{-3}$ in $\mathrm{Ni}_{2} \mathrm{Si}$, while it is $\sim 3 \times 10^{19}$ atom $\mathrm{cm}^{-3}$ in NiSi. The solubility limit found in $\mathrm{NiSi}$ is in agreement with the plateau observed in B profiles measured in NiSi after the reaction of Ni on B-implanted Si. () 2010 American Institute of Physics. [doi:10.1063/1.3303988]
\end{abstract}

The silicide NiSi is currently used in microelectronics to create metallic contacts on devices, ${ }^{1-3}$ especially in the 65 and $45 \mathrm{~nm}$ transistor technologies. NiSi is also considered for fully silicided gate applications ${ }^{4,5}$ and is the best candidate for 32 and $22 \mathrm{~nm}$ technology processes. Nevertheless, several difficulties need to be addressed in order to improve the integration of $\mathrm{NiSi}$ in the fabrication processes. ${ }^{6,7}$ For example, the encroachment phenomenon ${ }^{8}$ still decreases transistor production yield in the smaller technologies. As the surface area and thickness of NiSi layers are greatly decreasing in the future microelectronic structures, the contact quality can be deteriorated. ${ }^{9}$ Several routes are investigated in order to deal with this problem. ${ }^{9,10}$ Among them, the control of the dopant distribution in the NiSi layer and at its interface with silicon may play an important role in improving the electrical contact quality. ${ }^{5,6,11-13}$ Furthermore, as the lateral sizes of the device doped regions are also decreasing, the doping levels in Si are generally at maximum. Consequently, dopant behaviors during processes, such as diffusion, segregation, and clustering, need to be well controlled to assure good device performances. ${ }^{714} \mathrm{NiSi}$ contacts are produced using the salicide process. ${ }^{15}$ They result from the reaction of a Ni layer on Si that is usually highly doped (source, drain, and gate). In this process, a $\mathrm{Ni}_{2} \mathrm{Si}$ layer is formed and consumed before to form the NiSi layer of interest. ${ }^{16}$ In order to reduce the lateral diffusion of nickel, the salicidation process is usually performed using two rapid thermal annealing (RTA) steps. A low temperature RTA $\left(\sim 300{ }^{\circ} \mathrm{C}\right)$ is first performed to form $\mathrm{Ni}_{2} \mathrm{Si}$. Then, the unreacted nickel is removed before a second RTA performed at about $450{ }^{\circ} \mathrm{C}$, during which $\mathrm{Ni}_{2} \mathrm{Si}$ is transformed into NiSi. It is thus important to study dopant diffusion and stability in both $\mathrm{Ni}_{2} \mathrm{Si}$ and NiSi layers in order to understand their role on process defects and contact failure, as well as to understand and control their final distribution in the NiSi layer, which is in contact with both doped Si and the first level metal.

\footnotetext{
a) Author to whom correspondence should be addressed. Electronic mail: alain.portavoce@im2np.fr.
}

In this article, we describe experiments allowing better understanding of $\mathrm{B}$ redistribution during the salicide process on B-doped Si. Three following samples were produced: two samples were made for $\mathrm{B}$ diffusion studies either in $\mathrm{Ni}_{2} \mathrm{Si}$ or in $\mathrm{NiSi}$, and one sample was made to observe $\mathrm{B}$ redistribution resulting from the sequential formation of $\mathrm{Ni}_{2} \mathrm{Si}$ and $\mathrm{NiSi}$. The first two samples consisted of either a $250 \mathrm{~nm}$ thick polycrystalline $\mathrm{Ni}_{2} \mathrm{Si}$ layer or a $180 \mathrm{~nm}$-thick polycrystalline NiSi layer located between two $\mathrm{Si}$ oxide layers, the thickness of the surface oxide being $20 \mathrm{~nm}$ and the thickness of the oxide separating the silicides from the $\mathrm{Si}(001)$ substrate being $30 \mathrm{~nm}$. These silicides were produced through the reaction of a Ni layer deposited at room temperature by magnetron sputtering on a Si layer grown by low pressure chemical vapor deposition at $550{ }^{\circ} \mathrm{C}$ on the $30 \mathrm{~nm}$-thick oxide (see Ref. 17 for the description of sample fabrication and of silicide grain size stabilization procedures). A 5 $\times 10^{15}$ atom $\mathrm{cm}^{-2} \mathrm{~B}$ dose was implanted in these two silicide layers through the $20 \mathrm{~nm}$-thick $\mathrm{Si}$ oxide layer with a beam energy of 18 and $20 \mathrm{keV}$ in $\mathrm{NiSi}$ and $\mathrm{Ni}_{2} \mathrm{Si}$, respectively. Doping conditions were targeted in order to confine the entire boron dose within the top half of the silicide layer. The last sample consisted of a $70 \mathrm{~nm}$-thick Ni layer deposited at room temperature by magnetron sputtering on a $\mathrm{Si}(001)$ substrate previously implanted with a B dose of 1 $\times 10^{15}$ atom $\mathrm{cm}^{-2}$ using a beam energy of $10 \mathrm{keV}$. Before $\mathrm{Ni}$ deposition, the B-implanted $\mathrm{Si}$ substrate was annealed at $1050{ }^{\circ} \mathrm{C}$ for $30 \mathrm{~s}$ in order to activate the dopant. Pieces of these three samples were annealed all together either at 400, 450,500 , or $550^{\circ} \mathrm{C}$ for $1 \mathrm{~h}$ under vacuum $\left(\sim 10^{-7} \mathrm{Torr}\right)$. For these annealing conditions, the reaction of the $70 \mathrm{~nm}$ thick Ni layer on the B-implanted Si substrate gives, at the end of the thermal treatments, a single NiSi layer in contact with $\mathrm{Si}$. B concentration profiles were measured in the samples by secondary ion mass spectrometry (SIMS) using a $3 \mathrm{kV} \mathrm{Cs}^{+}$ion primary beam.

Figure 1 presents the B SIMS profiles measured in the $\mathrm{Ni}_{2} \mathrm{Si}$ layer after implantation, as well as after a following annealing at $400,450,500$, or $550{ }^{\circ} \mathrm{C}$ for $1 \mathrm{~h}$. The profiles measured after annealing correspond to the well known type $B$ diffusion kinetic regime in polycrystalline layers. ${ }^{17-19}$ The 


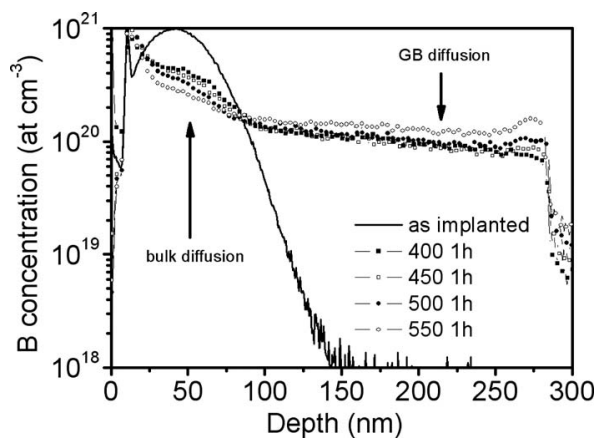

FIG. 1. B SIMS profiles measured in $\mathrm{Ni}_{2} \mathrm{Si}$ after the implantation of $5 \times 10^{15} \mathrm{~B}$ atom $\mathrm{cm}^{-2}$, and after annealing at $400,450,500$, or $550{ }^{\circ} \mathrm{C}$ for $1 \mathrm{~h}$.

diffusion profiles can be divided in two parts. A region close to the surface mainly depends on $\mathrm{B}$ diffusion in the $\mathrm{Ni}_{2} \mathrm{Si}$ grains (bulk or lattice diffusion), it corresponds to the decrease and the broadening of the initial Gaussian distribution. A deeper region essentially depends on $\mathrm{B}$ diffusion in the $\mathrm{Ni}_{2} \mathrm{Si}$ grain boundaries (GBs), it corresponds to the deep linear part of the profile. For every annealing temperature, all the atoms from the initial distribution are able to diffuse either in the grains or in the GBs, showing that the B solubility limit in $\mathrm{Ni}_{2} \mathrm{Si}$ is larger than the maximum concentration of the $\mathrm{B}$ implant, i.e., larger than $10^{21}$ atom $\mathrm{cm}^{-3}$. Indeed, dopant atoms contained in clusters are usually not mobile. ${ }^{19-21}$ If part of B atoms would have formed clusters, part of the B SIMS profiles would not change despite annealing. The B profiles are very similar for the four thermal treatments. At each temperature, B GB diffusion is fast enough to achieve a flat B concentration profile in GBs after $1 \mathrm{~h}$ annealing. The main difference between the four profiles comes from the profile part corresponding to bulk diffusion. The diffusion in the $\mathrm{Ni}_{2} \mathrm{Si}$ grains is stronger at higher temperature, but one notice that annealing at $400{ }^{\circ} \mathrm{C}$ for $1 \mathrm{~h}$ leads to an important flattening of the initial Gaussian distribution already, showing that the $\mathrm{B}$ lattice diffusion in $\mathrm{Ni}_{2} \mathrm{Si}$ is already quite important at $400{ }^{\circ} \mathrm{C}$.

Figure 2 shows the $\mathrm{B}$ concentration profiles measured in NiSi after implantation and after the same four thermal treatments. The B thermal redistribution is more complex in $\mathrm{NiSi}$ than in $\mathrm{Ni}_{2} \mathrm{Si}$, as it cannot be understood considering the diffusion phenomenon only. The B profiles can be divided in three following parts: I, II, and III in Fig. 2. In region I, we observe $\mathrm{B}$ diffusion from the bulk to the $\mathrm{NiSi} / \mathrm{SiO}_{2}$ interface. This phenomenon can be due to $\mathrm{B}$ segregation at this interface. A similar $\mathrm{B}$ accumulation at the $\mathrm{Ni}_{2} \mathrm{Si} / \mathrm{SiO}_{2}$ interface is

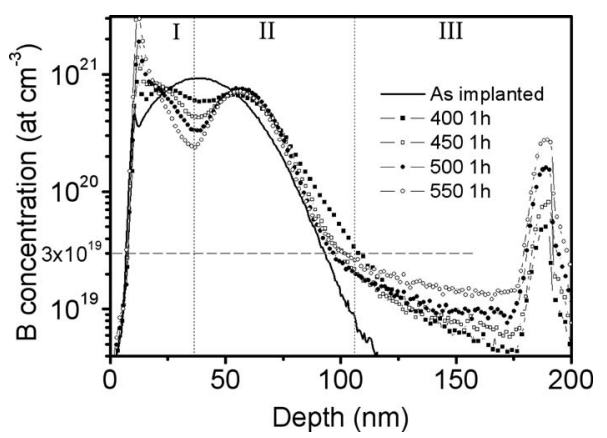

FIG. 2. B SIMS profiles measured in NiSi after the implantation of $5 \times 10^{15} \mathrm{~B}$ atom $\mathrm{cm}^{-2}$, and after annealing at $400,450,500$, or $550{ }^{\circ} \mathrm{C}$ for $1 \mathrm{~h}$.

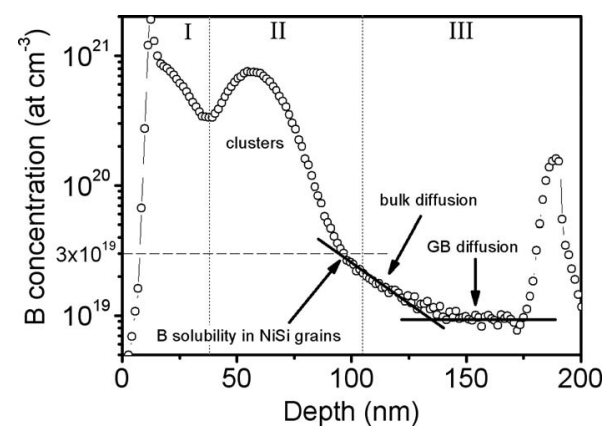

FIG. 3. B SIMS profile measured in NiSi after the implantation of $5 \times 10^{15} \mathrm{~B}$ atom $\mathrm{cm}^{-2}$, and after annealing at $500{ }^{\circ} \mathrm{C}$ for $1 \mathrm{~h}$.

also observed in Fig. 1. In region II, a new Gaussian-type B distribution appears as annealing temperature increases. This Gaussian has a smaller width than the initial Gaussian distribution, and its center is about $20 \mathrm{~nm}$ deeper in the NiSi layer than the initial distribution center. Its width decreases between the 400 and the $450{ }^{\circ} \mathrm{C}$ treatments, while it is about the same for higher annealing temperatures (right part of the Gaussian). The B atoms from this part of the profile are immobile during the heat treatments. Generally, this behavior corresponds to the formation of B clusters for concentration above solubility. ${ }^{19-21}$ The fact that the B cluster distribution follows a Gaussian distribution suggests that B cluster formation may result from heterogeneous nucleation on implantation-induced defects. B diffusion as well as B accumulation at the $\mathrm{NiSi} / \mathrm{SiO}_{2}$ interface are observed in region III. In the four SIMS profiles obtained after annealing, B atoms are mobile for concentration lower than $\sim 3$ $\times 10^{19}$ atom $\mathrm{cm}^{-3}$ only. Because diffusion occurs in a polycrystalline layer, two slopes can be observed in the diffusion profiles in region III. ${ }^{18}$ For clarity, Fig. 3 presents only the $\mathrm{B}$ concentration profile measured in $\mathrm{NiSi}$ after annealing at $500{ }^{\circ} \mathrm{C}$ for $1 \mathrm{~h}$. Two slopes are observed in region III. The first one is the signature of $\mathrm{B}$ lattice diffusion in NiSi (between 97 and $130 \mathrm{~nm}$ ), while the second is related to GB diffusion (between 130 and $175 \mathrm{~nm}$ ). Thus 3 $\times 10^{19}$ atom $\mathrm{cm}^{-3}$ corresponds to the solubility limit of B in NiSi. ${ }^{19-21}$ We notice that, at that temperature, the B GB diffusivity is high as the profile is flat in GBs. However, comparing the $\mathrm{B}$ diffusion profiles obtained in $\mathrm{Ni}_{2} \mathrm{Si}$ (Fig. 1) and NiSi (Fig. 2) under the same annealing conditions, B diffusion seems to be faster in $\mathrm{Ni}_{2} \mathrm{Si}$ than in $\mathrm{NiSi}$, as, for example, at $400{ }^{\circ} \mathrm{C}$, the $\mathrm{B}$ profile is flat in $\mathrm{Ni}_{2} \mathrm{Si}$ while it exhibits an obvious negative slope in NiSi.

Figure 4 presents the SIMS profiles measured in $\mathrm{NiSi}$ after the reaction of $70 \mathrm{~nm}$ of $\mathrm{Ni}$ on a B-implanted $\mathrm{Si}(001)$ substrate. The Si and Ni SIMS profiles are also shown. For clarity, the profile measured after annealing at $550{ }^{\circ} \mathrm{C}$ is not presented in Fig. 4, as it is superimposed with the profile measured at $500{ }^{\circ} \mathrm{C}$. The B profile measured in the sample before annealing $(70 \mathrm{~nm} \mathrm{Ni/B}$-doped $\mathrm{Si}$ ) has been added to this figure, despite that the comparison of this initial distribution to the one observed in NiSi is highly questionable due to density differences between $\mathrm{Ni}, \mathrm{Ni}_{2} \mathrm{Si}, \mathrm{NiSi}$, and $\mathrm{Si}$ and the redistribution effects. Three regions can be observed in Fig. 4. Region I corresponds to the NiSi layer and region III corresponds to the Si substrate. The region II is located between NiSi and $\mathrm{Si}$. In this region, the Ni concentration decreases and the Si concentration increases, but the slopes of the Ni and Si signals contain usual SIMS artifacts ${ }^{22,23}$ that 


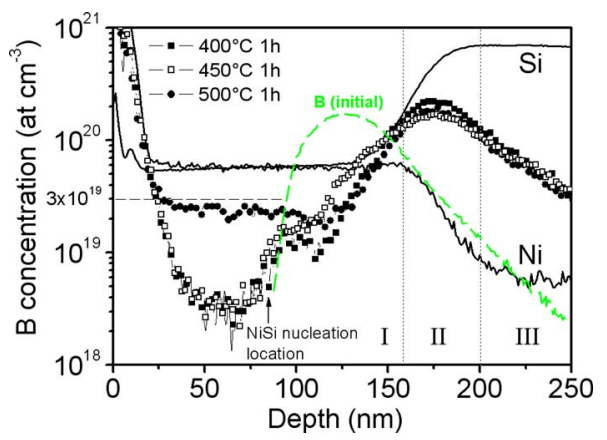

FIG. 4. (Color online) B SIMS profiles measured in NiSi after the reaction of a $70 \mathrm{~nm}$-thick Ni layer on a B-implanted $\mathrm{Si}(001)$ substrate at 400,450 , or $500{ }^{\circ} \mathrm{C}$ for $1 \mathrm{~h}$. The Ni and Si profiles corresponding to the $550{ }^{\circ} \mathrm{C}$ annealing are also shown (solid lines), as well as the initial B profile measured in the sample before annealing (dashed line).

prevent definitive conclusion regarding whether the B maximum concentration is in the substrate, at the $\mathrm{NiSi} / \mathrm{Si}$ interface or in a real Ni-Si mixed layer. However, transmission electron microscopy has shown that the $\mathrm{NiSi} / \mathrm{Si}$ interface is usually quite abrupt. ${ }^{24}$ Furthermore, B diffusion should not occur in the Si substrate in our annealing conditions, ${ }^{25}$ while it should be observable in $\mathrm{NiSi}$, since the $\mathrm{Si}$ substrate is monocrystalline and the NiSi layer is polycrystalline. Thus, part of region II is probably located in the Si substrate. Considering the atomic densities of $\mathrm{Ni}, \mathrm{Si}$, and $\mathrm{NiSi}$, the consumption of $70 \mathrm{~nm}$ of $\mathrm{Ni}$ should produce a $\sim 153 \mathrm{~nm}$-thick $\mathrm{NiSi}$ layer, which give a NiSi/Si interface located close to the $\mathrm{B}$ concentration peak. The profiles measured after annealing at 400 and $450{ }^{\circ} \mathrm{C}$ show a similar step in the B profile. One can notice that this step is located approximately in the middle of the NiSi layer, which corresponds to the initial location of NiSi nucleation, since NiSi grows at the two $\mathrm{Ni}_{2} \mathrm{Si} / \mathrm{NiSi}$ and $\mathrm{NiSi} / \mathrm{Si}$ interfaces. Furthermore, an important $\mathrm{B}$ surface segregation is observed in the profiles. This step in the B profiles can be understood considering the observations made in the implanted silicide layers (Figs. 1-3). Indeed, several stages can be expected during the sequential phase formation process. (i) During $\mathrm{Ni}_{2} \mathrm{Si}$ growth, $\mathrm{B}$ can diffuse from the bulk to the $\mathrm{Ni} / \mathrm{Ni}_{2} \mathrm{Si}$ interface (or to the surface), because of fast $\mathrm{B}$ diffusion in $\mathrm{Ni}_{2} \mathrm{Si}$ and due to interface (or surface) B segregation. This phenomenon drains the $\mathrm{B}$ atoms from the $\mathrm{Ni}_{2} \mathrm{Si}$ layer, while increases B concentration at the surface (left part of SIMS profiles). This mechanism could be altered if the Ni film would be caped by a nonreacting layer changing $\mathrm{B}$ segregation properties. (ii) $\mathrm{NiSi}$ nucleates at the $\mathrm{Ni}_{2} \mathrm{Si} / \mathrm{Si}$ interface. (iii) During $\mathrm{NiSi}$ growth, despite that $\mathrm{B}$ can continue to diffuse in the consumed $\mathrm{Ni}_{2} \mathrm{Si}$ layer up to the surface, the $\mathrm{B}$ profile in $\mathrm{NiSi}$ should not be drastically changed in the left side of the profiles $\left(\mathrm{Ni}_{2} \mathrm{Si} / \mathrm{NiSi}\right.$ interface growth), as the $\mathrm{B}$ concentration is lower than the B solubility in NiSi. In contrast, in the right part of the B profiles (NiSi/Si interface growth), B redistribution can result from the snow plow effect. ${ }^{26}$ Furthermore, the $\mathrm{B}$ amount plowed away during this stage could result also from B segregation or a former snow plow effect at the $\mathrm{Ni}_{2} \mathrm{Si} / \mathrm{Si}$ interface. At 500 and $550{ }^{\circ} \mathrm{C}$, the step becomes a plateau that goes through the entire NiSi layer up to the surface. NiSi formation occurs generally at about $250{ }^{\circ} \mathrm{C} .{ }^{16}$ Consequently, B redistribution follows two following stages during our annealing: (i) the B distribution is modified during the phase formations and (ii) $\mathrm{B}$ diffuses once the $\mathrm{NiSi}$ layer is formed. After the formation of the step in the B profile in NiSi, B should diffuse in the NiSi polycrystalline layer at a maximum concentration equal to its solubility limit. This is in agreement with the results obtained at 500 and $550{ }^{\circ} \mathrm{C}$. The fact that the profiles are the same at 500 and $550{ }^{\circ} \mathrm{C}$ supports the idea that $\mathrm{B}$ has reached an equilibrium limit. Furthermore, the plateau concentration is found at about $\sim 3 \times 10^{19} \mathrm{~B}$ atom $\mathrm{cm}^{-3}$, which confirms the B solubility limit determined from Fig. 2 .

In conclusion, $\mathrm{B}$ redistribution in implanted $\mathrm{Ni}_{2} \mathrm{Si}$ and NiSi layers has been studied and compared to B redistribution during the reaction of a $\mathrm{Ni}$ film deposited on a B-implanted $\mathrm{Si}(001)$ substrate, in same annealing conditions. B diffusion seems faster in $\mathrm{Ni}_{2} \mathrm{Si}$ than in NiSi. After annealing, cluster formation has not been observed in $\mathrm{Ni}_{2} \mathrm{Si}$ for $\mathrm{B}$ concentration as high as $10^{21}$ atom $\mathrm{cm}^{-3}$. In contrast, B clusters formed in the NiSi layer, giving a B solubility limit of about $3 \times 10^{19}$ atom $\mathrm{cm}^{-3}\left(400-550{ }^{\circ} \mathrm{C}\right)$. For the highest annealing temperatures, the $\mathrm{B}$ plateau observed in the concentration profiles measured in $\mathrm{NiSi}$ after the reaction of the Ni layer with the B-implanted Si substrate can be explained by $\mathrm{B}$ diffusion in NiSi up to its solubility limit.

${ }^{1}$ C. Lavoie, F. M. d'Heurle, C. Detavernier, and C. Cabral, Jr., Microelectron. Eng. 70, 144 (2003).

${ }^{2}$ S. Bonnetier, B. Imbert, M. Hopstaken, D. Galpin, R. Gwoziecki, D. Barge, S. Zoll, O. Anilturk, E. Sicurani, C. Caillat, A. Barr, R. Gonella, Y. Espinoux, P. Mur, N. Mayet, A. Gotti, and M.-T. Basso, Microelectron. Eng. 84, 2528 (2007).

${ }^{3}$ C. W. Kuo, S. L. Wu, S. J. Chang, H. Y. Lin, and Y. P. Wang, J. Electrochem. Soc. 155, H611 (2008).

${ }^{4}$ W. P. Maszara, J. Electrochem. Soc. 152, G550 (2005).

${ }^{5}$ J. Liu and D. L. Kwong, Appl. Phys. Lett. 88, 192111 (2006).

${ }^{6}$ K.-M. Chang, J.-H. Lin, and C.-Y. Sun, Appl. Surf. Sci. 254, 6151 (2008).

${ }^{7}$ P. Ahmet, T. Shiozawa, K. Nagahiro, T. Nagata, K. Kakushima, K. Tsutsui, T. Chikyow, and H. Iwai, Microelectron. Eng. 85, 1642 (2008).

${ }^{8}$ J. Seger, P.-E. Hellström, J. Lu, B. G. Malm, M. von Haartman, M. Östling, and S.-L. Zhang, Appl. Phys. Lett. 86, 253507 (2005).

${ }^{9}$ P. Kalra, N. Vora, P. Majhi, P. Y. Hung, H.-H. Tseng, R. Jammy, and T.-J. King Liu, Electrochem. Solid-State Lett. 12, H1 (2009).

${ }^{10}$ H.-S. Wong, L. Chan, G. Samudra, and Y.-C. Yeo, Appl. Phys. Lett. 93, 072103 (2008).

${ }^{11}$ M. Copel, R. P. Pezzi, and C. Cabral, Jr., Appl. Phys. Lett. 86, 251904 (2005).

${ }^{12}$ J. Liu and D. L. Kwong, Electrochem. Solid-State Lett. 9, G334 (2006).

${ }^{13}$ J. Knoch, M. Zhang, S. Feste, and S. Mantl, Microelectron. Eng. 84, 2563 (2007).

${ }^{14}$ P. Zhao, M. J. Kim, B. E. Gnade, and R. M. Wallace, Microelectron. Eng. 85, 54 (2008).

${ }^{15}$ H. Iwai, T. Ohguro, and S.-I. Ohmi, Microelectron. Eng. 60, 157 (2002).

${ }^{16}$ D. Mangelinck and K. Hoummada, Appl. Phys. Lett. 92, 254101 (2008).

${ }^{17}$ I. Blum, A. Portavoce, D. Mangelinck, R. Daineche, K. Hoummada, J. L. Lábár, V. Carron, and C. Perrin, J. Appl. Phys. 104, 114312 (2008).

${ }^{18}$ A. Portavoce, G. Chai, L. Chow, and J. Bernardini, J. Appl. Phys. 104 104910 (2008).

${ }^{19}$ A. Portavoce, R. Simola, D. Mangelinck, J. Bernardini, and P. Fornara, Diffus. Defect Data 264, 33 (2007).

${ }^{20}$ A. Portavoce, P. Gas, I. Berbezier, A. Ronda, J. S. Christensen, A. Yu. Kuznetsov, and B. G. Svensson, Phys. Rev. B 69, 155415 (2004).

${ }^{21}$ A. Portavoce, D. Mangelinck, R. Simola, R. Daineche, and J. Bernardini, Defect Diffus. Forum 289-292, 329 (2009).

${ }^{22}$ K. Hoummada, D. Mangelinck, C. Perrin, V. Carron, and P. Holliger, J. Appl. Phys. 104, 024313 (2008).

${ }^{23}$ A. Portavoce, N. Rodriguez, R. Daineche, C. Grosjean, and C. Girardeaux, Mater. Lett. 63, 676 (2009).

${ }^{24}$ Y.-L. Jiang, A. Agarwal, G.-P. Ru, X.-P. Qu, J. Poate, B.-Z. Li, and W. Holland, Appl. Phys. Lett. 85, 410 (2004).

${ }^{25}$ J. S. Christensen, H. H. Radamson, A. Yu. Kuznetsov, and B. G. Svensson, Appl. Phys. Lett. 82, 2254 (2003).

${ }^{26}$ M. Wittmer and T. E. Seidel, J. Appl. Phys. 49, 5827 (1978). 